\title{
Study of membrane cleaning with and without ultrasounds application after fouling with three model dairy solutions
}

\author{
M.J. Luján-Facundo*, J.A. Mendoza-Roca, B. Cuartas-Uribe, S. Álvarez-Blanco
}

Instituto de Seguridad Industrial, Radiofísica y Medioambiental, Universitat Politècnica de València, Camino de Vera, s/n, Valencia 46022, Spain.

Tel. +34963876386

e-mail: malufa@etsii.upv.es

\begin{abstract}
The aim of this study was to investigate the behaviour of two ultrafiltration (UF) membranes after their fouling with different fouling solutions and cleaning with a surfactant, including the application of ultrasounds (US). Thus, two UF membranes (UH030 and UP005) were fouled with three different whey model solutions that consisted of bovine serum albumin (BSA) with a concentration of $1 \% \mathrm{w} / \mathrm{w}, \mathrm{BSA}(1 \%$ w/w) plus $\mathrm{CaCl}_{2}$ with a concentration of $0.17 \%$ w/w and whey solution (Renylat 45 ) with a concentration of $2.22 \% \mathrm{w} / \mathrm{w}$. Chemical cleaning was carried out with P3 Ultrasil 115 solution at temperatures between $25^{\circ} \mathrm{C}$ and $45^{\circ} \mathrm{C}$ and concentrations in the range between $0.5 \% \mathrm{v} / \mathrm{v}$ and $0.9 \% \mathrm{v} / \mathrm{v}$. US were applied in some of the tests at a frequency of $20 \mathrm{kHz}$ and nominal power of $300 \mathrm{~W}$. The results demonstrated that US cleaning was
\end{abstract}


effective to enhance the permeability recovery, although this enhancement was only up to $9 \%$. Concerning fouling, results from resistances calculations showed that for UH030 membrane prevails the reversible fouling whereas for UP005 membrane predominate irreversible fouling.

Keywords: Ultrasounds; ultrafiltration; model dairy solutions; fouling; membrane cleaning.

\section{Nomenclature list}

\begin{tabular}{|c|c|}
\hline$U F$ & ultrafiltration \\
\hline$U S$ & ultrasounds \\
\hline$P S$ & polysulfone \\
\hline$B S A$ & bovine serum albumin \\
\hline$T M P$ & transmembrane pressure \\
\hline$K$ & membrane permeability; $\mathrm{L} \cdot \mathrm{m}^{-2} \cdot \mathrm{h}^{-1} \cdot \mathrm{bar}^{-1}$ \\
\hline$\Delta P$ & transmembrane pressure applied; bar \\
\hline$C_{p}$ & permeate protein concentration; $\mathrm{mg} \cdot \mathrm{mL}^{-1}$ \\
\hline$C_{f}$ & feed protein concentration; $\mathrm{mg} \cdot \mathrm{mL}^{-1}$ \\
\hline$\mu$ & irreversible resistance; $\mathrm{m}^{-1}$ \\
\hline$J_{w}$ & permeate flux with destilled water; $\mathrm{L} \cdot \mathrm{m}^{-2} \cdot \mathrm{h}^{-1}$ \\
\hline$J_{t}$ & permeate flux at the end of the fouling step; $\mathrm{L} \cdot \mathrm{m}^{-2} \cdot \mathrm{h}^{-1}$ \\
\hline$J_{w r l}$ & permeate flux after the first rinsing step; $\mathrm{L} \cdot \mathrm{m}^{-2} \cdot \mathrm{h}^{-1}$ \\
\hline$J_{w c}$ & permeate flux after the second rinsing step; $\mathrm{L} \cdot \mathrm{m}^{-2} \cdot \mathrm{h}^{-2}$ \\
\hline$C E$ & cleaning efficiency without US; \% \\
\hline$C E_{\text {test with US }}$ & cleaning efficiency applying US; \% \\
\hline$C E_{U S}$ & cleaning efficiency improvement with US; $\%$ \\
\hline$R_{m}$ & membrane initial hydraulic resistance, $\mathrm{m}^{-1}$ \\
\hline$R_{t}$ & membrane resistance after fouling step, $\mathrm{m}^{-1}$ \\
\hline$R_{c}$ & membrane resistance after the second rinsing step, $\mathrm{m}^{-1}$ \\
\hline$R_{\text {irrev }}$ & irreversible resistance; $\mathrm{m}^{-1}$ \\
\hline$R_{\text {rev }}$ & reversible resistance; $\mathrm{m}^{-1}$ \\
\hline
\end{tabular}




\section{Introduction}

Membrane technologies are frequently used for many industrial applications (Delaunay et al., 2008). Especially, in the dairy industry, UF membranes are commonly used for processes such as milk dehydration and whey concentration (Kazemimoghadam and Mohammadi, 2007).

UF processes present many advantages over conventional processes such as the reduction of the cost of separation operations (due to low-energy requirement) and the increasing of the product yield. However, the main concern of UF processes is membrane fouling, since retained particles can accumulate on the membrane surface and inside the pores (Muthukumaran et al., 2004). As a result, an important reduction in the separation efficiency by decreasing the permeate flux is produced. In membranes used in dairy industry, proteins and minerals (mainly calcium and phosphorous) are the two major contributors to membrane fouling (Rice et al., 2009). These compounds foul the membrane by adsorption onto the membrane surface and due to internal pore blockage.

For the restoration of the membrane initial permeability, it is necessary to clean the membranes. Thus, optimization of the cleaning processes for UF membranes (Yee et al., 2009) is of paramount importance. Most works about membrane cleaning are focused on conventional cleaning methods using chemicals such as acids, bases, chelating agents or surfactants. However, these methods often require large amounts of chemicals and make the membrane cleaning process more expensive. Besides, the excessive use of these chemicals can damage the membrane material and decrease the lifetime of the 
membrane. Thus, it is important to study and to develop other cleaning methods that reduce the use of these products.

In the last years the use of US in the membrane cleaning process has been taken into account (Muthukumaran et al., 2004). In the membrane processes field, US have been applied both in the cleaning membrane procedures (like in this study) to remove the fouling and in membrane filtration processes to prevent it (Kyllönen et al., 2006; Secondes et al., 2014; Muthukumaran et al., 2005b). Membrane cleaning with US uses high-frequency sound waves to create microbubbles that collapse, with a release of energy, which help to remove foulant from the membrane surface, since the interaction between foulant and membrane is weakened. In addition, the high pressures and temperatures generated with the collapsing of microbubbles are a source of $-\mathrm{OH}$ radicals, which may lead to the oxidation of organic pollutants and molecules at the gasliquid interface (Naddeo et al., 2014).

Several authors have studied the use of US in membrane applications. As reported by (Muthukumaran et al., 2005b; Muthukumaran et al., 2007), US applications at low frequencies were effective both for the filtration and the cleaning of UF membranes treating whey. Popović et al., (2010) published that US membrane cleaning was effective for ceramic membranes used for whey ultrafiltration. Muthukumaran et al., (2004) studied the effect of US in combination with surfactant solution for cleaning polysulfone flat sheet ultrafiltration membranes used for whey ultrafiltration. These authors reported that US cleaning were effective and independent of the sonication time. However, in these studies membrane modules were submerged in the US bath instead of applying US in the cleaning solution like in this study. 
The main purpose of this work was to study the protein separation effectiveness and membrane fouling of two ultrafiltration (UF) membranes fouled by model proteins solutions (BSA $1 \% \mathrm{w} / \mathrm{w}$ and $0.06 \% \mathrm{w} / \mathrm{w}$ in calcium dosed as $\mathrm{CaCl}_{2}$ ) and commercial whey. In addition, it was evaluated the membrane cleaning, under several cleaning operation conditions, including the application of ultrasounds (US). For this, US were applied in the chemical cleaning solution instead of submerging the membrane module in the US bath, what has been reported in the literature by most authors until now (Kyllönen et al., 2006; Latt and Kobayashi, 2006; Li et al., 2002; Muthukumaran et al., 2005a). Thus, in this study, membrane module was placed outside the US bath, US were generated in the chemical cleaning solution that was recirculated by the membrane system.

As a cleaning agent a specific surfactant, P3 Ultrasil 115, has been tested. Surfactant solutions are common chemical cleaning agents used to restore the membrane initial flux. Particularly, P3 Ultrasil 115 is recommended to clean membranes used in the dairy industry and to remove organic foulants like proteins (Naim et al., 2012). In this work, the membrane flux recovery for various P3 Ultrasil 115 solutions at three temperatures and concentrations was evaluated. US were applied to enhance the flux recovery and to evaluate their effect under different cleaning conditions.

\section{Materials and methods}

\subsection{Ultrafiltration pilot plant}


A laboratory UF plant (Orelis Environnement SAS, Salindres, France) was used in the experiments. This laboratory plant includes a Rayflow flat sheet module also from Orelis, France. The membrane module has capacity for two flat sheet membranes of 100 $\mathrm{cm}^{2}$ each one, operating by cross-flow filtration mode and working in series. The US equipment consisted of a US bath and US generator. The tank for the cleaning solution, where US were generated was a TSD-D 18 ultrasonic bath (TSD Machinery, Ultrasonidos JJ.VICEDO, Valencia, Spain) with total volume of 18 L. This tank was connected to US generator TSD RF 300 (TSD Machinery). Ultrasonic equipment consists of an ultrasound generator and special transducers. The produced ultrasonic waves propagate through the liquid medium (like the chemical cleaning solution), causing a succession of compression and expansion cycles. This sequence of events is called cavitation phenomenon and is the responsible to promoting cleaning. The collapse of the bubbles cause the breakup between the foulant and the membrane and remove the foulant from the membrane (Li et al., 2002; Muthukumaran et al., 2005a). A scheme of the UF plant is shown in Fig. 1. 


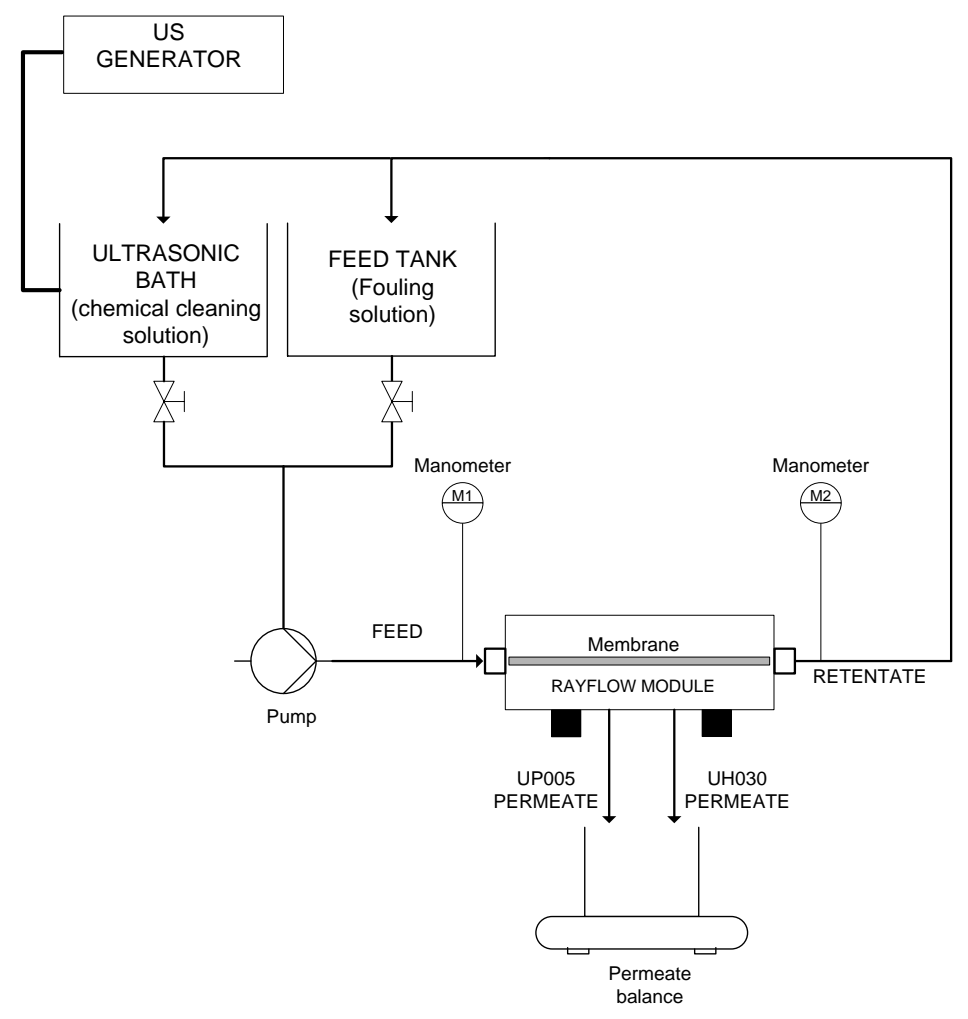

Figure 1: Schematic diagram of UF plant.

\subsection{Membranes}

The organic UF membranes tested in the experiments were from Microdyn Nadir (Wiesbaden, Germany). Two types of membranes were used. One of them was a polyethersulfone (PES) membrane with a nominal molecular weight cut-off of $5 \mathrm{kDa}$ (membrane UP005) and the other one was a hydrophilic polyethersulfone (PESH) membrane with a nominal molecular weight cut-off of $30 \mathrm{kDa}$ (membrane UH030). Both membranes accept values of $\mathrm{pH}$ in the range of $0-14$ and work until temperatures of $95^{\circ} \mathrm{C}$. 


\subsection{Materials}

Fouling experiments were carried out using three different aqueous solutions: BSA, $\mathrm{BSA} / \mathrm{CaCl}_{2}$ and whey solutions. BSA (purity $>98 \%$ ) was provided by Sigma Aldrich (Madrid, Spain), $\mathrm{CaCl}_{2}$ (95\% purity) was supplied from Panreac AppliChem (Barcelona, Spain) and whey solution Renylat 45 with a total protein content of $45 \%$ was purchased from Reny Picot (Asturias, Spain). The first one consisted of bovine serum albumin with a concentration of $1 \% \mathrm{w} / \mathrm{w}$. The second one was a mixture of BSA with a concentration of $1 \% \mathrm{w} / \mathrm{w}$ plus $\mathrm{CaCl}_{2}$ with a concentration of $0.06 \% \mathrm{w} / \mathrm{w}$ in calcium. Finally, the last one was a commercial whey solution and it was prepared at a protein concentration of $2.22 \% \mathrm{w} / \mathrm{w}$. All these compounds were supplied in powder form, were dissolved in deionized water and were stored at $4^{\circ} \mathrm{C}$.

Membranes were cleaned with surfactant P3 Ultrasil 115 aqueous solutions (Ecolab, Valencia, Spain) at a $\mathrm{pH}$ ranging from 12.49-12.89.

To analyze the Renylat 45 composition different methods were applied. Lactose was quantified by Chloramine T iodometric method (Norma UNE 34826/1983, 1983), bicinchoninic acid method (BCA, Sigma Aldrich, Madrid, Spain) was used for total protein determination (Smith et al., 1987). Fat content was determined by using a Fourier transform infrared spectroscopy (FTIR) model MilkoScan FT120 (Gerber Instruments AG, Effretikon, Switzerland). A “790 Personal IC" chromatograph equipped with a Metrosep C 2150 column (both supplied by Metrohm, Herisau Switzerland) was employed to determine the amount of individual cations. Ash content was measured following the method of incineration in a furnace at $540{ }^{\circ} \mathrm{C}$ following the 
AOAC method indications 930.30 (AOAC Official Method 930.30, Ash of Dried Milk, First Action, 1930).

\subsection{Zeta potential and particle size of fouling solutions}

Mean diameter and zeta potential of the three different solutions (BSA, $\mathrm{BSA} / \mathrm{CaCl}_{2}$ and Renylat 45) were measured by Zetasizer Nano ZS90 (Malvern Instruments, Malvern, United Kingdom). On one hand, mean diameter was determined by the software from an average intensity calculated by the apparatus. Renylat 45 was diluted 10 times for a better particle size analysis since this sample had a complex composition and it was not possible its analysis without a previous dilution. On the other hand, the zeta potential of the fouling solution was measured at the $\mathrm{pH}$ (7.5) of the feed solution in the fouling experiments.

\subsection{Experiments and measurements}

\subsubsection{Initial and final permeability}

Membrane permeability was measured at the beginning and end of each experiment to evaluate the effectiveness of the cleaning procedure. Membrane permeability $(\mathrm{K})$ is given in $\mathrm{L} \cdot \mathrm{m}^{-2} \cdot \mathrm{h}^{-1} \cdot$ bar $^{-1}$ and was evaluated by means of Eq. 1 :

$$
\mathrm{K}=
$$

$\frac{\mathrm{J}_{\mathrm{W}}}{\Delta \mathrm{P}}$ 
Where $\mathrm{J}_{\mathrm{w}}$ is the permeate flux measured with distilled water and $\Delta \mathrm{P}$ is the applied transmembrane pressure (TMP) in bar. Permeability measurements were carried out with distilled water at $25^{\circ} \mathrm{C}$.

\subsubsection{Fouling experiments}

The membrane fouling tests were carried out at a transmembrane pressure of 2 bar and at a cross-flow velocity of $2 \mathrm{~m} \cdot \mathrm{s}^{-1}$. The temperature of the fouling solution was maintained at $25^{\circ} \mathrm{C}$ and the duration of the fouling step was $2 \mathrm{~h}$. During the fouling stage permeate flux and rejection were measured to check that the values obtained were reproducible in all the experiments.

Protein rejection coefficient was calculated from measuring the permeate protein concentration $\left(\mathrm{C}_{\mathrm{p}}\right)$ during the fouling experiments. On one hand, protein permeate concentrations were determined by an UV-visible spectrophotometer (Hewlett-Packard $8453)$ at the wavelength equivalent for the maximum BSA absorbance ( $278 \mathrm{~nm})$. By contrast, protein rejection during Renylat 45 fouling was measured by using the Bradford Assay Kit. To perform a Bradford assay, $0.1 \mathrm{ml}$ of each permeate sample was added to $3 \mathrm{ml}$ of Bradford reagent, after stirring and leaving at room temperature between 20 and 30 minutes, their absorbencies at $595 \mathrm{~nm}$ of wavelength were measured. Rejection coefficient was calculated as follows (Eq.2), where $\mathrm{C}_{\mathrm{f}}$ is the protein concentration in the feed solution $(1 \% \mathrm{w} / \mathrm{w})$.

Protein rejection $(\%)=\left(1-\frac{C_{p}}{C_{f}}\right) \cdot 100$

\subsubsection{Cleaning experiments}


The cleaning methodology included a first rinsing step with distilled water, a chemical cleaning step (with P3 Ultrasil 115 where US were applied in some tests) and a second rinsing step also with distilled water (without TMP) for 5 min before carried out the final permeability measurement.

The first rinsing step was carried out at fixed experimental conditions for all tests: TMP of $1 \mathrm{bar}, 25^{\circ} \mathrm{C}$ of temperature, cross flow velocity of $2.2 \mathrm{~m} \cdot \mathrm{s}^{-1}$ and duration of $30 \mathrm{~min}$.

Cleaning experiments were performed with P3 Ultrasil 115 solution at three different temperatures $\left(25,35\right.$ and $\left.45^{\circ} \mathrm{C}\right)$ with three different surfactant concentrations $(0.5,0.7$ and $0.9 \% \mathrm{v} / \mathrm{v})$. These values have been chosen following the surfactant manufacturer indications and according to the experimental conditions tested by other authors (Astudillo et al., 2010; Popović et al., 2010; Rabiller-Baudry et al., 2002). The pH of the tested surfactant solutions varied from 12.7 to 12.9 . Table 1 summarizes the experimental chemical cleaning conditions (temperature and concentration). Transmembrane pressure, cleaning step duration and cross flow velocity during the chemical cleaning step were fixed at $1 \mathrm{bar}, 30 \mathrm{~min}$ and $2.2 \mathrm{~m} \cdot \mathrm{s}^{-1}$, respectively.

US were generated in the chemical cleaning solution at $300 \mathrm{~W}$ of nominal power and $20 \mathrm{kHz}$ of frequency and they were applied in the chemical cleaning step. These values of power and frequency have been chosen according to a previous study (LujánFacundo et al., 2013). Therefore, for each fouling solution a total of 9 different experiments were carried out (as it has been described in Table 1). If cleaning efficiencies without US application were higher than 95\%, the results of the same experiment but using US in the cleaning step were not showed. Each experiment (initial permeability, fouling, cleaning and final permeability) was repeated at least twice. If the difference in the cleaning efficiency values was higher than $5 \%$, the experiment was 
repeated and the mean values have been reported. Finally, if the initial permeability of the membranes was not recovered after each test (at least with a recovery value of 95\%) an extra cleaning procedure was carried out before beginning the next experiment.

Table 1: Experimental P3 Ultrasil 115 conditions during the chemical cleaning.

\begin{tabular}{cccccccccc}
\hline Test number & $\mathbf{1}$ & $\mathbf{2}$ & $\mathbf{3}$ & $\mathbf{4}$ & $\mathbf{5}$ & $\mathbf{6}$ & $\mathbf{7}$ & $\mathbf{8}$ & $\mathbf{9}$ \\
\hline Temperature $\left({ }^{\circ} \mathbf{C}\right)$ & 25 & 35 & 45 & 25 & 35 & 45 & 25 & 35 & 45 \\
Concentration $(\mathbf{\%} \mathrm{v} / \mathbf{v})$ & 0.5 & 0.5 & 0.5 & 0.7 & 0.7 & 0.7 & 0.9 & 0.9 & 0.9 \\
\hline
\end{tabular}

\subsubsection{Statistical analysis of the results}

As previously stated in Section 2.5.3, a series of runs were performed varying the chemical cleaning conditions. In this way, three different temperatures $(25,35$ and $\left.45^{\circ} \mathrm{C}\right)$ and three different surfactant concentrations $(0.5 \% \mathrm{v} / \mathrm{v}, 0.7 \% \mathrm{v} / \mathrm{v}$ and $0.9 \% \mathrm{v} / \mathrm{v})$ were tested. All the experiments were carried out with and without US. In addition, as commented above (Section 2), two membranes (UH030 and UP005) and three different fouling solutions were tested. Thus, a total of 108 experiments were analyzed. Each experiment was repeated at least twice and if the difference in the cleaning efficiency was higher than 5\%, the experiment was repeated three times. A statistical analysis was carried out with STATGRAPHICS Centurion XVI to study the statistical significant differences with the different factors and their interactions by means of an ANOVA multifactorial analysis with a confidence level of $95 \%$. In this way, the dependent variable was the cleaning efficiency and the 5 factors studied were the following ones: temperature, concentration, membrane type, fouling solution and use of ultrasounds. 
2.5.5. Evaluation of cleaning efficiency and US efficiency.

The efficiency of the cleaning procedure was determined according to Eq. 3 defined by Matzinos and Álvarez, (2002). This parameter was used to evaluate the efficiency of the cleaning protocol to restore the membrane initial permeability:

$\mathrm{CE}(\%)=\frac{\mathrm{R}_{\mathrm{t}}-\mathrm{R}_{\mathrm{c}}}{\mathrm{R}_{\mathrm{t}}-\mathrm{R}_{\mathrm{m}}} \cdot 100$

All the resistances were calculated from Darcy's law. $R_{m}$ is the membrane initial hydraulic resistance, calculated with Eq. 4 using the initial water flux $\left(\mathrm{J}_{\mathrm{w}}\right)$ measured at the beginning of the experiment; $\mathrm{R}_{\mathrm{t}}$ is the membrane resistance after the fouling step calculated from Eq. 4, changing $J_{w}$ by membrane flux at the end of the fouling step $\left(J_{t}\right)$; $R_{c}$ is the membrane resistance after the second rinsing step, calculated using Eq. 4 replacing $\mathrm{J}_{\mathrm{w}}$ by the cleaned membrane flux $\left(\mathrm{J}_{\mathrm{wc}}\right)$ measured at the end of the cleaning step after the second rinsing water.

$R_{m}=\frac{\Delta P}{\mu \cdot J_{w}}$

Irreversible resistance $\left(R_{\text {irrev }}\right)$ and reversible resistances $\left(R_{\text {rev }}\right)$ were calculated following Eq. 5 and Eq. 6. $\mathrm{J}_{\mathrm{wr} 1}$ is the water flux after the first rinsing step.

$\mathrm{R}_{\text {irrev }}=\frac{\Delta \mathrm{P}}{\mu \cdot \mathrm{J}_{\mathrm{wr} 1}}-\mathrm{R}_{\mathrm{m}}$ 
$\mathrm{R}_{\mathrm{t}}=\mathrm{R}_{\mathrm{rev}}+\mathrm{R}_{\text {irrev }}+\mathrm{R}_{\mathrm{m}}$

In addition, Eq. 7 (Muthukumaran et al., 2005b) was used to study the improvement in

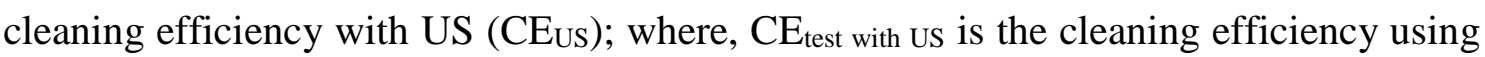
US and CE is the cleaning efficiency without US application.

$\mathrm{CE}_{\mathrm{US}}=\frac{\mathrm{CE}_{\text {test with US }}-\mathrm{CE}}{\mathrm{CE}}$ 


\section{Results and discussion}

\subsection{Whey characterization}

Renylat 45 composition was analyzed following the procedure commented in Section 2.3. As expected, the main components were lactose $(63.72 \% \mathrm{w} / \mathrm{w})$ and proteins $(38.144 \%$ w/w). Although there were many ions presented in Renylat 45 solution, like phosphates $(0.441 \% \mathrm{w} / \mathrm{w})$, magnesium $(0.224 \% \mathrm{w} / \mathrm{w})$ or sulphates $(0.080 \% \mathrm{w} / \mathrm{w})$ among others, the ions measured in a greater proportion were potassium $(1.560 \% \mathrm{w} / \mathrm{w})$, sodium $(1.210 \% \mathrm{w} / \mathrm{w})$, chloride $(1.128 \% \mathrm{w} / \mathrm{w})$ and calcium $(0.711 \% \mathrm{w} / \mathrm{w})$. In addition, Renylat 45 presents a fat and ash content of $0.20 \% \mathrm{w} / \mathrm{w}$ and $6.01 \% \mathrm{w} / \mathrm{w}$, respectively. Several authors (Cuartas-Uribe et al., 2009; Macedo et al., 2011) showed very similar whey solution composition. It is important to highlight, as stated by other authors (Gsan et al., 1995; Merin, U., 1980), that in dairy industry the main components involved in membrane fouling are proteins and ions, mainly calcium.

3.2. Fouling solutions characteristics: particle size and zeta potential

Table 2 shows the zeta potential of fouling solutions at the $\mathrm{pH}$ of the feed solution in the fouling experiments $(\mathrm{pH}$ 7.5) and the average size of the colloids in the fouling solutions, whose characteristics have been reported in section 2.3. Results shown that BSA and $\mathrm{BSA} / \mathrm{CaCl}_{2}$ solutions had a very similar average size $(9.04$ and $10.14 \mathrm{~nm}$, 
respectively) what implies that the increase in ionic strength in the solution did not entail a change in the BSA average size. By contrast, Renylat 45 solution showed a higher average size $(971 \mathrm{~nm})$ than BSA solutions and, in this case, average size is a good index of particles aggregation (Surh et al., 2006). Renylat 45 solution is a very heterogeneous sample (as it was showed in Section 3.1) what implies a wide spread of particle size. According to previous literature, a great variability of results of average particle size was found for whey solutions. (Narong and James, 2008) reported an average whey particle size of $5.3 \mu \mathrm{m}$. Elsewhere, (Kulmyrzaev et al., 2000) measured particle size of whey solution and found and average particle size of $0.53 \mu \mathrm{m}$. Fig. 2 shows the particle size distribution of the three fouling solutions. The measure of each sample was repeated three times. It is important to observe the formation of BSA aggregates in BSA solution, wich was not observed when calcium chloride was added.

At the $\mathrm{pH}$ of the feed solution in the fouling experiments $(\mathrm{pH} 7.5)$ the zeta potential was negative for all the fouling solutions. Salt concentration affected zeta potential since $\mathrm{BSA} / \mathrm{CaCl}_{2}$ solution showed higher zeta potential than BSA solution. This fact is due to the adsorption of calcium ions onto BSA particles what moderate the negative surface charge of the colloids (Dukhin and Parlia, 2014; Yang et al., 2010). Renylat 45 also showed a negative zeta potential. These results were in concordance with previous studies (Jun et al., 2011; Kuzmenko et al., 2005). Thus, it can be concluded that all the organics foulants at the $\mathrm{pH}$ of fouling solution (around 7.5) were charged negatively.

Table 2: Fouling solutions characteristics.

\begin{tabular}{llll}
\hline Fouling solution & BSA & BSA/CaCl & Renylat 45 \\
\hline Size (diameter, nm) & $9.04 \pm 0.99$ & $10.14 \pm 2.52$ & $971.08 \pm 36.98$ \\
Zeta potential $(\mathbf{m V})$ & $-44.06 \pm 1.98$ & $-8.36 \pm 1.57$ & $-28.55 \pm 4.45$ \\
\hline
\end{tabular}

a) 


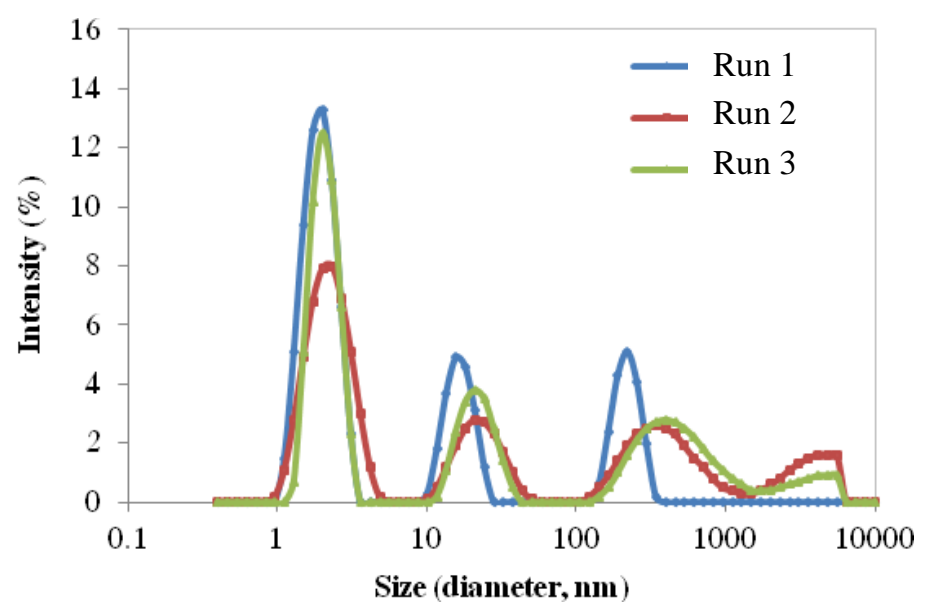

b)

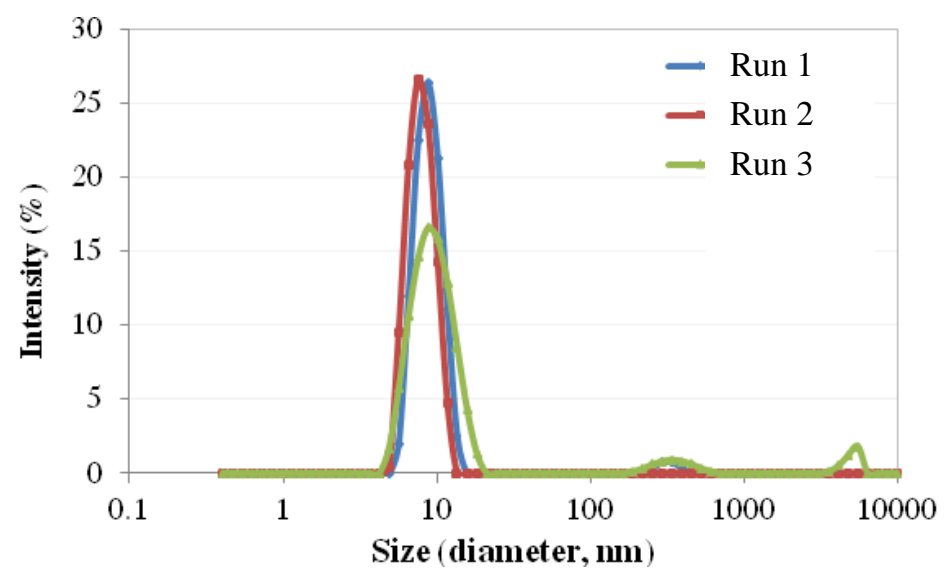

c)

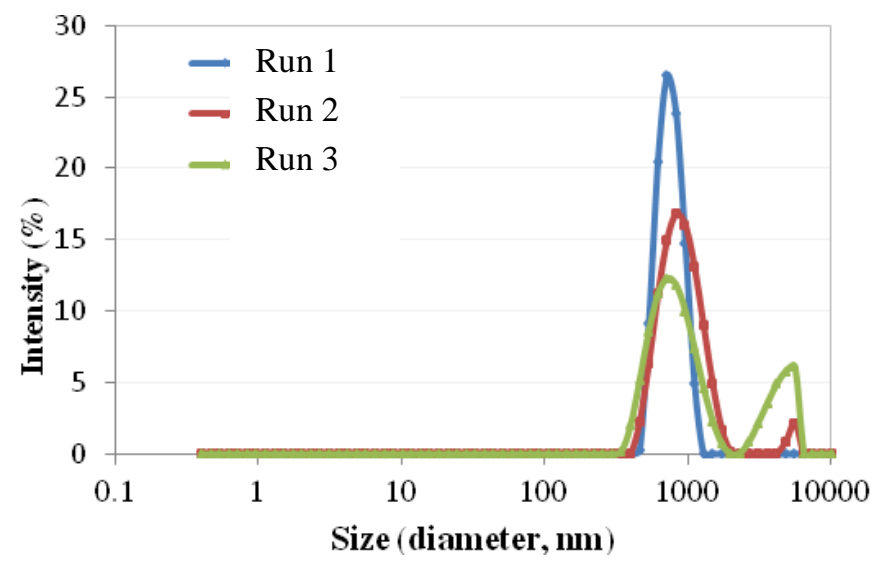

Figure 2: Particle size distribution for a) $\mathrm{BSA}, \mathrm{b}) \mathrm{BSA} / \mathrm{CaCl}_{2}$ and c) Renylat 45.

3.3. Membrane fouling 
Fig. 3 and Fig. 4 show the evolution of the permeate flux of the three feed streams with time for UH030 and UP005 membranes at a transmembrane pressure of 2 bar, at crossflow velocity of $2 \mathrm{~m} \cdot \mathrm{s}^{-1}$ and at temperature of $25^{\circ} \mathrm{C}$. The highest permeate fluxes for both membranes were obtained when BSA solutions were filtered. The lowest permeate flux corresponded with the filtration of Renylat 45 solution. Permeate fluxes decreased significantly in the first 20 minutes, especially for UP005 membrane, meanwhile the flux decay was very slight the following 40 minutes. Finally, fluxes reached a constant value. The flux reduction percentages (considering the stable value reached after 120 minutes) have been included in Fig. 3 and Fig. 4 for UH030 and UP005 membranes, respectively. For UH030, these values were $20.22 \%, 20.48 \%$ and $26.60 \%$ for BSA, $\mathrm{BSA} / \mathrm{CaCl}_{2}$ and Renylat 45, respectively. By contrast, for UP005 membrane, these values were $35.03 \%, 29.29 \%$ and $28.38 \%$ for $\mathrm{BSA}, \mathrm{BSA} / \mathrm{CaCl}_{2}$ and Renylat 45 , respectively. Flux reduction in the first minutes was caused by concentration polarization which is very common in membrane processes, especially in filtration of low molecular-weight solutes or macromolecules like proteins (Nigam et al., 2008). Concentration polarization is an inevitable but reversible phenomenon and it does not affect the intrinsic properties of the membrane. The retained components were accumulated gradually near the membrane surface. This phenomenon may cause the formation of a dense cake layer and it may also block the membrane pores. Fouling layer formation is due to physicochemical interactions between the whey or proteins and the membrane. This fact is commonly related with the charge of the membrane and the foulant.

As mentioned above, at $\mathrm{pH} 7.5$ all the fouling solutions had negative charge. In a previous study (Luján-Facundo et al., 2013), it was reported that both membranes tested 
presented also a negative zeta potential (-6.33 and -8.07 for membrane UH030 and UP005, respectively). Thus it seems that the charge was not a significant factor in membrane fouling since proteins and membrane are charged negatively. In spite of this, protein molecules have both negative and positive zones, what could allow localized interactions between proteins and membrane (Tan et al., 2014). In addition, Nakanishi et al., (2001) have demonstrated that many whey proteins classified as soft proteins (including BSA, $\alpha$-lactoalbumin and $\beta$-casein) have low internal stability and tend to adsorb on all surfaces, independently of electrostatic interactions.

The presence of calcium increased the membrane fouling (Shi et al., 2014), not only due to precipitation, but also because it can form a bridge between the proteins and membrane, as well as between the proteins (Cheryan, 1998; Ramachandra Rao, 2002). Finally, Renylat 45 was the feed stream that caused the highest membrane fouling according to the flux decline values. This fact is related with its composition, since fouling increases faster when lactose and salts are presented in solutions (Hausmann et al., 2013). In addition, Renylat 45 is the foulant with the highest content of $\mathrm{Ca}^{+2}, 7.1 \mathrm{~g} / \mathrm{l}$, as it was shown in Section 3.1. It led to a higher membrane fouling.

Comparing both membranes, it has to be mentioned that, as expected, the membrane with the largest pore size, UH030 membrane, always yielded the highest flux. 


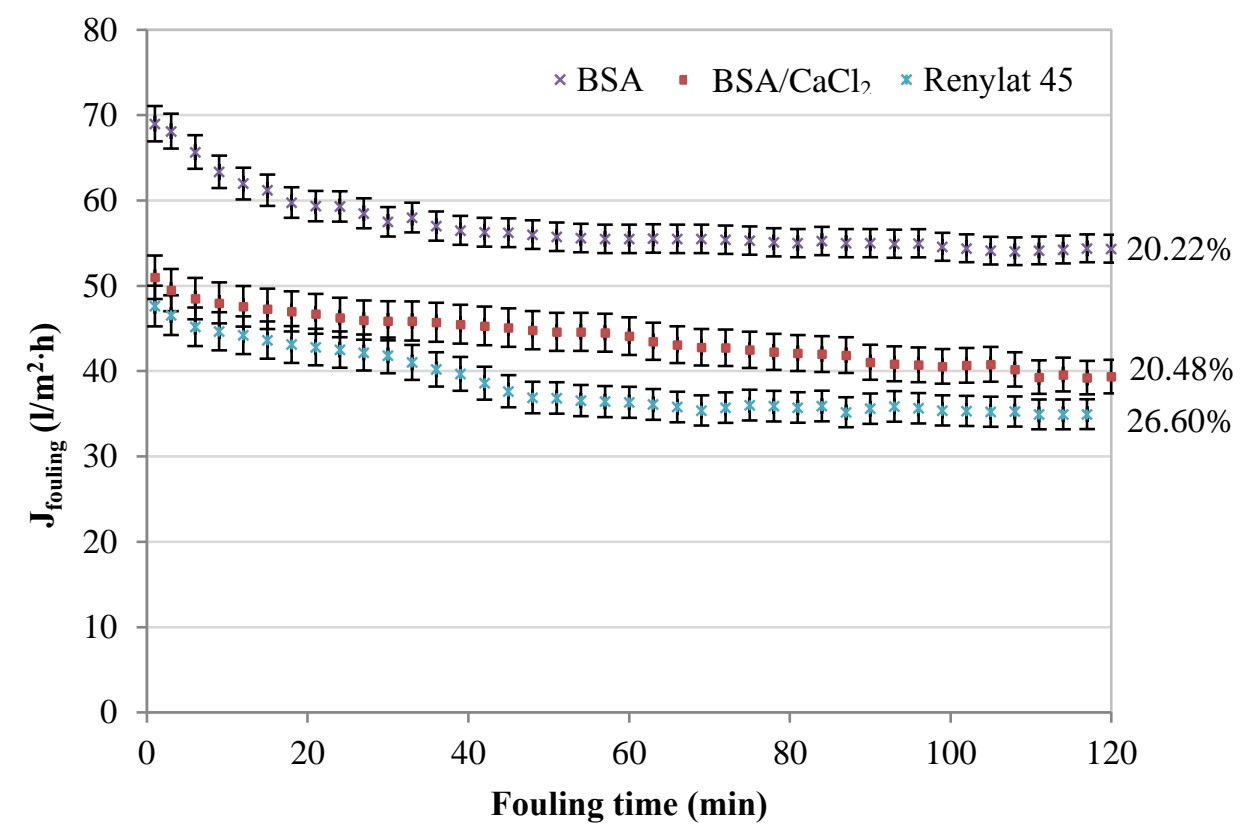

Figure 3: Evolution of UH030 membrane permeate flux with time during fouling experiments.

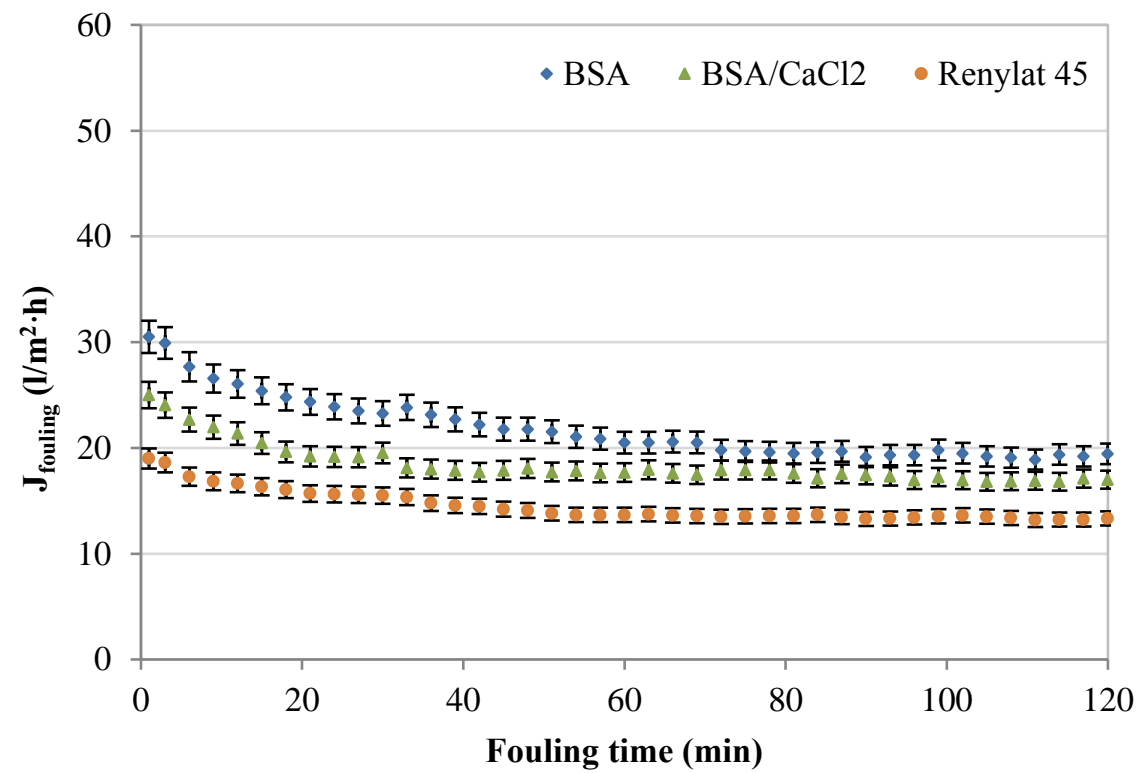

Figure 4: Evolution of UP005 membrane permeate flux with time during fouling experiments.

\subsection{Membrane resistances}

To compare the fouling type of the two membranes, membrane resistances $R_{m}, R_{\text {rev }}$ and $\mathrm{R}_{\text {irrev }}$ were calculated as explained in Section 2.5.4. Figure 5 shows the mean values 
calculated for each membrane and fouling solution. $R_{m}$ values of each membrane peace differ slightly each other, since the membrane sheet is not completely uniform; thereby different pieces could present different permeability values. It can be observed that for all the feed streams, reversible fouling was more severe for UH030 than for UP005 as it was reported in a previous study (Luján-Facundo et al., 2013). By contrast, the irreversible fouling in UP005 membrane prevails, what corroborates earlier works (Luján-Facundo et al., 2013). These results could be explained taking into account the different pore size and characteristics (zeta potential, roughness and contact angle) of the membrane material. On one hand, UP005 has smaller pore size than UH030 what could explain that the UP005 membrane was more susceptible to irreversible adhesion of proteins as other authors also reported (Bae and Tak, 2005; Qu et al., 2014). On the other hand, UH030 shows worse antifouling properties in terms of zeta potential, contact angle and roughness (more negative zeta potential, higher contact angle and higher roughness value) (Luján-Facundo et al., 2015), what implies that proteins could be attached easier to the membrane surface and cause reversible fouling.

Resistances results were in concordance with previous results discussed in Section 3.3. since Renylat 45 was the most fouling feed stream. As expected, with increasing calcium concentration $\left(0.6 \mathrm{~g} / \mathrm{l}\right.$ and $7.1 \mathrm{~g} / \mathrm{l}$ for $\mathrm{BSA} / \mathrm{CaCl}_{2}$ and Renylat 45 , respectively) resistances were higher. Proteins, lactose and salt contained in Renylat 45 seemed to form a more extensive layer on the membrane surface than BSA proteins, and this was probably due to the stronger interactions of these components with the membrane (Hausmann et al., 2013). Reversible and irreversible resistances percentages for each membrane remained very similar for the three different fouling solutions. 


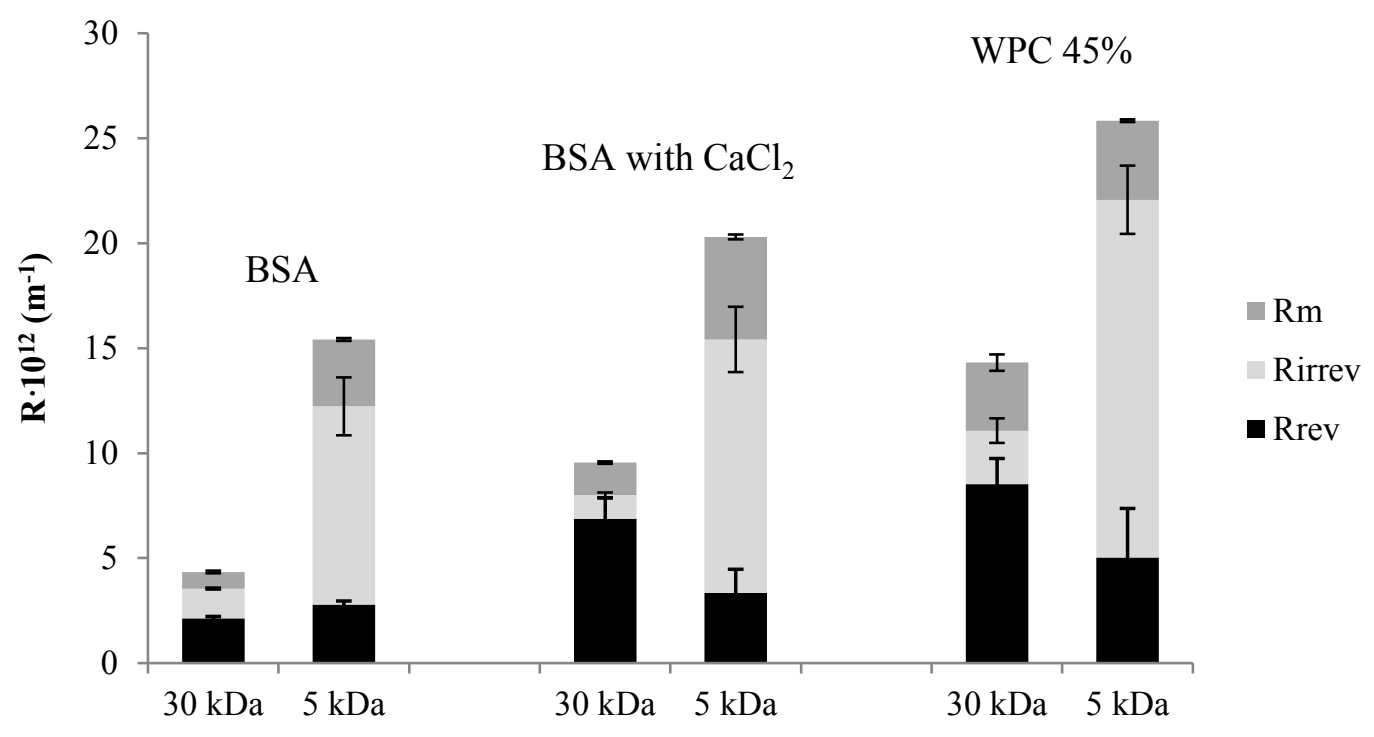

Figure 5: Membrane resistances for the three different fouling solutions.

\subsection{Membranes rejection}

Figure 6 shows the evolution of the proteins rejection percentage with time during the fouling step for both membranes tested and for BSA and Renylat 45 solutions. As it can be observed, the protein rejection increased with fouling time due to pore blocking and the rejection achieved steady-state values near $100 \%$ after about 80 min of operation for both membranes and fouling solutions tested. For both fouling solutions, UH030 membrane always showed lower rejection coefficient than UP005 as expected due to their MWCO (Schäfer et al., 2000). If both fouling solutions are compared, proteins from whey were rejected in a greater extent than BSA. This is related to the fact that Renylat 45 showed higher average size than BSA, as it was observed in Table 2. Related to $\mathrm{BSA} / \mathrm{CaCl}_{2}$ fouling solution, previous studies (Marshall et al., 2003; Teng et al., 2006) have reported that salt concentration increases the rejection percentages. In this way, since BSA (fouling solution without any salt solution added) rejection percentages values were almost $100 \%, \mathrm{BSA} / \mathrm{CaCl}_{2}$ rejection percentages were also practically $100 \%$ (data not shown). 


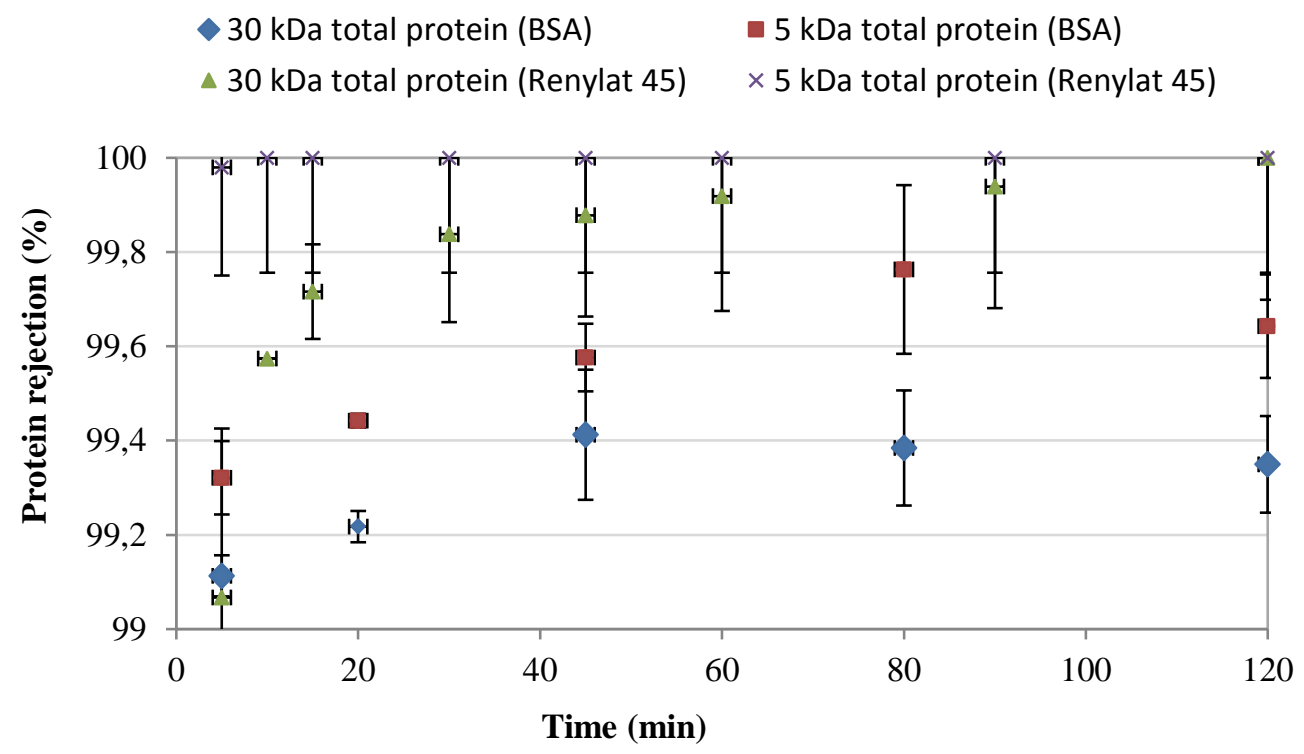

Figure 6: Evolution of rejection with time.

3.6. Effect of temperature and surfactant concentration on cleaning efficiency

The effect of concentration and temperature of the cleaning solution (P3 Ultrasil 115) on cleaning efficiency was studied. In this way, as it has been shown in Table 1, concentration and temperature of the cleaning solution were varied from $0.5 \% \mathrm{v} / \mathrm{v}$ to $0.9 \% \mathrm{v} / \mathrm{v}$ and $25^{\circ} \mathrm{C}$ to $45^{\circ} \mathrm{C}$, respectively. Nine experiments were carried out following the criteria explained in the materials and methods section (section 2.5.3). In order to evaluate the cleaning efficiency, the optimum values were those producing the highest cleaning efficiency for the same experimental operating conditions (transmembrane pressure, flow rate, cleaning time and resistance at the beginning of the cleaning process).

Taking into account cleaning efficiencies values shown in Table 3 and Table 4, when BSA solution was used as fouling solution, the highest value was $100 \%$ for both membranes and it was achieved at a P3 Ultrasil 115 concentration of $0.7 \%$ for both membranes, at temperatures of $35^{\circ} \mathrm{C}$ and $45^{\circ} \mathrm{C}$ for $\mathrm{UH} 030$ membrane and at $45^{\circ} \mathrm{C}$ for 
UP005 membrane. When $\mathrm{BSA} / \mathrm{CaCl}_{2}$ was used as fouling solution, the highest value was also $100 \%$ for both membranes and it was achieved at a concentration of $0.5 \%$ and temperature of $45^{\circ} \mathrm{C}$ for both membranes. Finally, when membranes were fouled with Renylat 45 the highest value was $96 \%$ for both membranes and it was achieved with a concentration of $0.7 \%$ and a temperature of $45^{\circ} \mathrm{C}$ and with a concentration of $0.7 \%$ and a temperature of $35^{\circ} \mathrm{C}$ for membranes UH030 and UP005, respectively.

Other authors (Kazemimoghadam and Mohammadi, 2007; Kuzmenko et al., 2005; Muthukumaran et al., 2005b) reported that cleaning efficiency was affected by cleaning agents conditions. In this way, higher concentrations of cleaning agents significantly contribute to diffusion of the chemicals to the membrane surface and pore. Regarding with temperature effect, the diffusivity coefficient increases as temperature rises. Thus, the rate of transfer of fouling molecules from the membrane towards the bulk solution is greater. In addition, the structural stability of the fouling layer and its swelling are influenced by high temperatures leading fouling removal from the membrane surface (Lee and Elimelech, 2007). However, in this study no differences on the cleaning efficiency were found for the three concentrations of P3 Ultrasil 115. On the contrary, the effect of the temperature on the cleaning efficiency was the espected, according to the literature previously cited. 
Table 3: Cleaning efficiency with and without US for UH030 membrane.

\begin{tabular}{|c|c|c|c|c|c|c|c|c|c|}
\hline \multirow{3}{*}{ Test } & \multicolumn{3}{|c|}{ BSA } & \multicolumn{3}{|c|}{$\mathrm{BSA} / \mathrm{CaCl}_{2}$} & \multicolumn{3}{|c|}{ Renylat 45} \\
\hline & \multicolumn{2}{|c|}{ Cleaning efficiency $(\%)$} & \multirow{2}{*}{$\mathrm{CE}_{\mathrm{US}}(\%)$} & \multicolumn{2}{|c|}{ Cleaning efficiency $(\%)$} & \multirow{2}{*}{ CEus (\%) } & \multicolumn{2}{|c|}{ Cleaning efficiency (\%) } & \multirow{2}{*}{ CEus (\%) } \\
\hline & Without US & With US & & Without US & With US & & Without US & With US & \\
\hline 1 & 95 & - & - & 97 & - & - & 93 & 92 & 0 \\
\hline 2 & 94 & 97 & 3 & 97 & - & - & 86 & 92 & 7 \\
\hline 3 & 95 & - & - & 100 & - & - & 95 & - & - \\
\hline 4 & 83 & 87 & 5 & 99 & - & - & 91 & 96 & 5 \\
\hline 5 & 100 & - & - & 94 & 100 & 6 & 93 & 97 & 4 \\
\hline 6 & 100 & - & - & 93 & 99 & 6 & 96 & - & - \\
\hline 7 & 87 & 93 & 6 & 99 & - & - & 88 & 92 & 4 \\
\hline 8 & 99 & - & - & 96 & - & - & 93 & 95 & 2 \\
\hline 9 & 94 & 97 & 3 & 94 & 97 & 3 & 95 & - & - \\
\hline
\end{tabular}


Table 4: Cleaning efficiency with and without US for UP005 membrane.

\begin{tabular}{|c|c|c|c|c|c|c|c|c|c|}
\hline \multirow{3}{*}{ Test } & \multicolumn{3}{|c|}{ BSA } & \multicolumn{3}{|c|}{$\mathrm{BSA} / \mathrm{CaCl}_{2}$} & \multicolumn{3}{|c|}{ Renylat 45} \\
\hline & \multicolumn{2}{|c|}{ Cleaning efficiency $(\%)$} & \multirow{2}{*}{ CEus (\%) } & \multicolumn{2}{|c|}{ Cleaning efficiency (\%) } & \multirow{2}{*}{ CEus (\%) } & \multicolumn{2}{|c|}{ Cleaning efficiency (\%) } & \multirow{2}{*}{ CEus (\%) } \\
\hline & Without US & With US & & Without US & With US & & Without US & With US & \\
\hline 1 & 86 & 91 & 5 & 92 & 93 & 1 & 94 & 86 & 0 \\
\hline 2 & 95 & - & - & 99 & - & - & 88 & 85 & 0 \\
\hline 3 & 95 & - & - & 100 & - & - & 94 & 100 & 6 \\
\hline 4 & 90 & 87 & 0 & 96 & - & - & 86 & 88 & 2 \\
\hline 5 & 91 & 100 & 9 & 97 & - & - & 96 & - & - \\
\hline 6 & 100 & - & - & 93 & 95 & 2 & 93 & 93 & 0 \\
\hline 7 & 92 & 93 & 1 & 90 & 100 & 10 & 81 & 85 & 5 \\
\hline 8 & 98 & - & - & 99 & - & - & 90 & 90 & 0 \\
\hline 9 & 93 & 98 & 5 & 97 & - & - & 95 & - & - \\
\hline
\end{tabular}




\subsection{Effect of ultrasound on cleaning efficiency}

The experiments carried out to evaluate the effect of US on cleaning efficiency were performed at the same fouling and cleaning experimental conditions (reported in section 2.5.3). It is important clarify that US were applied in the chemical cleaning step, i.e. results indicate the ability of US to remove the irreversible fouling.

It was observed in Table 3 and Table 4 that for almost every test using US slightly higher cleaning efficiency values than those achieved without ultrasound application at the same cleaning conditions were obtained. The enhancement percentage (\%) was between $0 \%$ and $7 \%$ for membrane UH030, and between $0 \%$ and $9 \%$ for membrane UP005 across the full range of our experiments (taking into account the three different fouling solutions). It is important to remark that CE values with and without US for both membranes, could not be very different since CE values without US application were already very high.

On the one hand, US effectiveness is due to the enhancement of the cake layer removal and the decrease of the pores blocking because of the collapse of the microbubbles created by US (Duriyabunleng et al., 2001). On the other hand, the US irradiation to the Ultrasil solution helps to accelerate the reaction of the detergent with the proteins accumulated on the membrane (Maskooki et al., 2008). These results were in concordance with other authors (Muthukumaran et al., 2007; Muthukumaran et al., 2005b; Popović et al., 2010), who studied the US application to membrane cleaning employed in wastewater from dairy industry. Muthukumaran et al., 2005 studied the effect of US combined with a detergent in the PS membrane cleaning fouled with whey solution. This group of researchers showed that cleaning was more effective for high 
temperatures of the cleaning solution, $\mathrm{pH}$ around 12 , surfactant concentration close to the critical micellar concentration and for low pressures applied. The enhancement in the cleaning efficiency was between 5\% and 10\%. Maskooki et al., 2008 applied US in the PVDF membrane cleaning previously used in the dairy industry. Results reported that the enhancement of the cleaning efficiency was around $8 \%$ and they were achieved using EDTA at a concentration between 1-3 mM.

\subsection{Statistical analysis}

Results from variance analysis showed that the factors temperature, use of US, membrane type and fouling solution were statistically significant factors since the $\mathrm{p}$ value were lower than 0.05 . Fig. 7 shows the Tukey diagrams for the statistically significant factors. As it can be observed, for the factors "temperature", "use of ultrasounds", "membrane type" and "fouling solution" there were statistically significant differences between the different levels studied since the vertical lines do not overlap. Concerning to the temperature Tukey diagram (Fig. 7.a), it is important to highlight that there were not statistically significant differences in cleaning efficiency values between the temperatures $35^{\circ} \mathrm{C}$ and $45^{\circ} \mathrm{C}$ since the vertical lines overlap.

Regarding the factors interactions, there were statistical significant differences between membrane-temperature, fouling solution-temperature, and temperature-concentration. The influence of these interactions on the cleaning efficiency has been stated in Fig. 8. It seems clear from Fig. 8.a and 8.b that cleaning efficiency increases as increases temperature for both membranes and for the three fouling solutions. In addition, as 
commented above, the increase in cleaning efficiency is more pronounced between the temperatures $25^{\circ} \mathrm{C}$ and $35^{\circ} \mathrm{C}$ than between $35^{\circ} \mathrm{C}$ and $45^{\circ} \mathrm{C}$.

a)

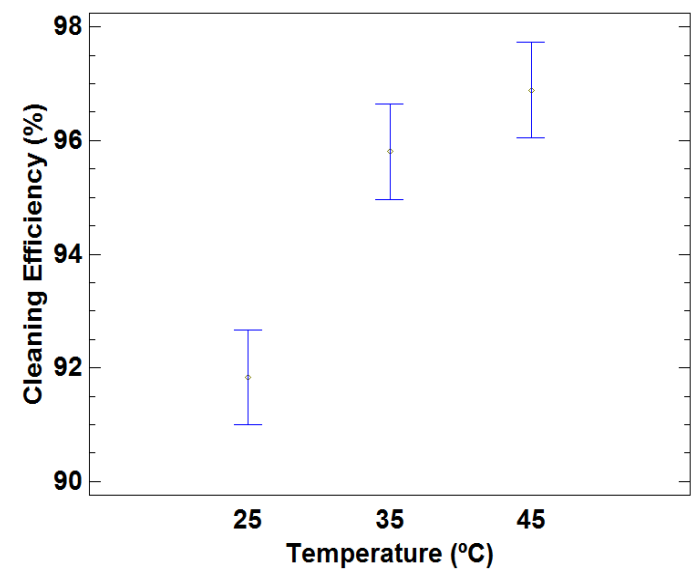

b)

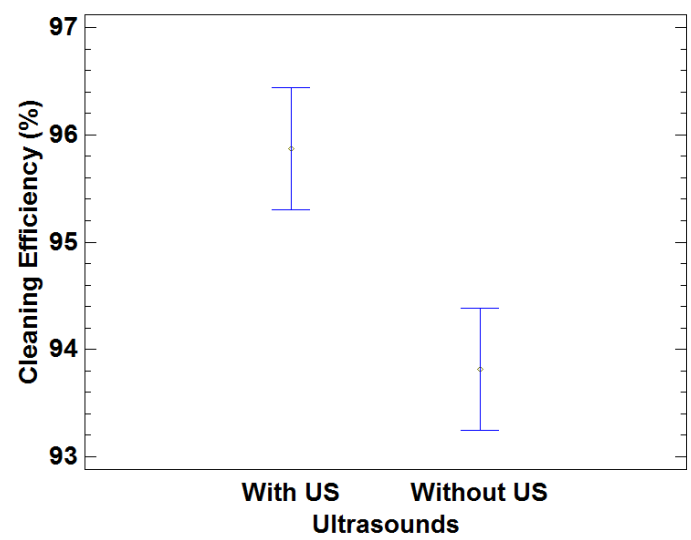

c)

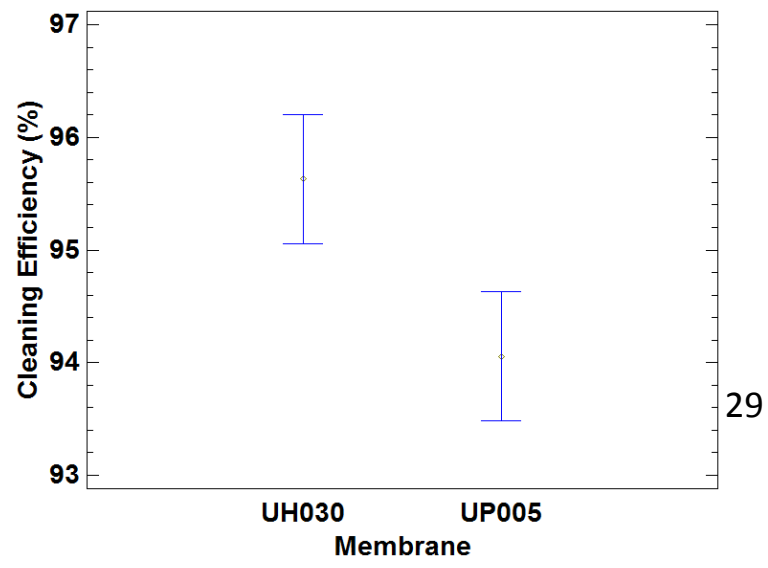


d)

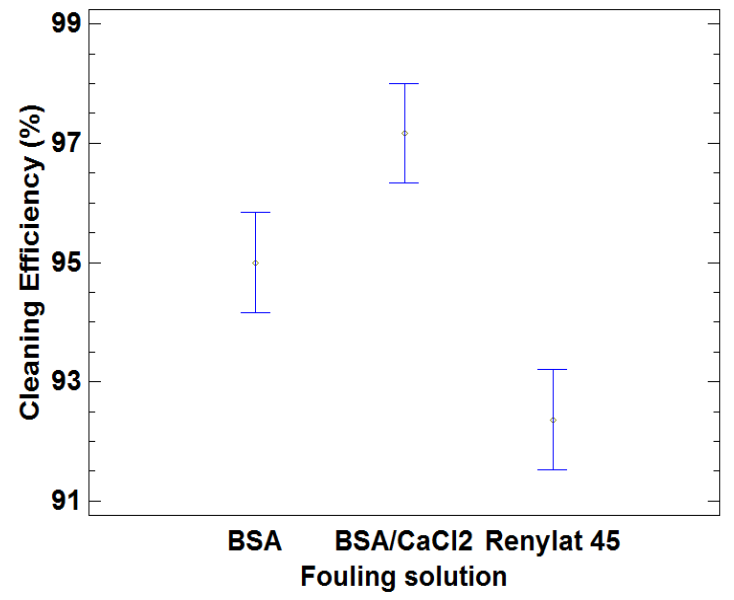

Figure 7: Tukey diagram from ANOVA analysis for the different factors: a) temperature, b) use of ultrasounds, c) member type and d) fouling solution.

a)

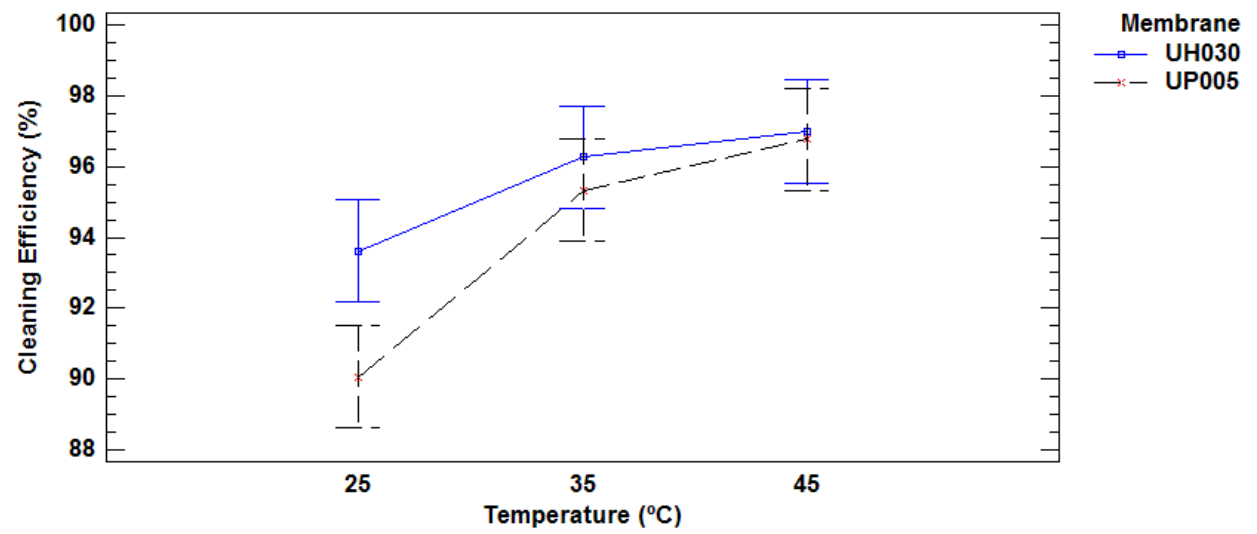

b) 

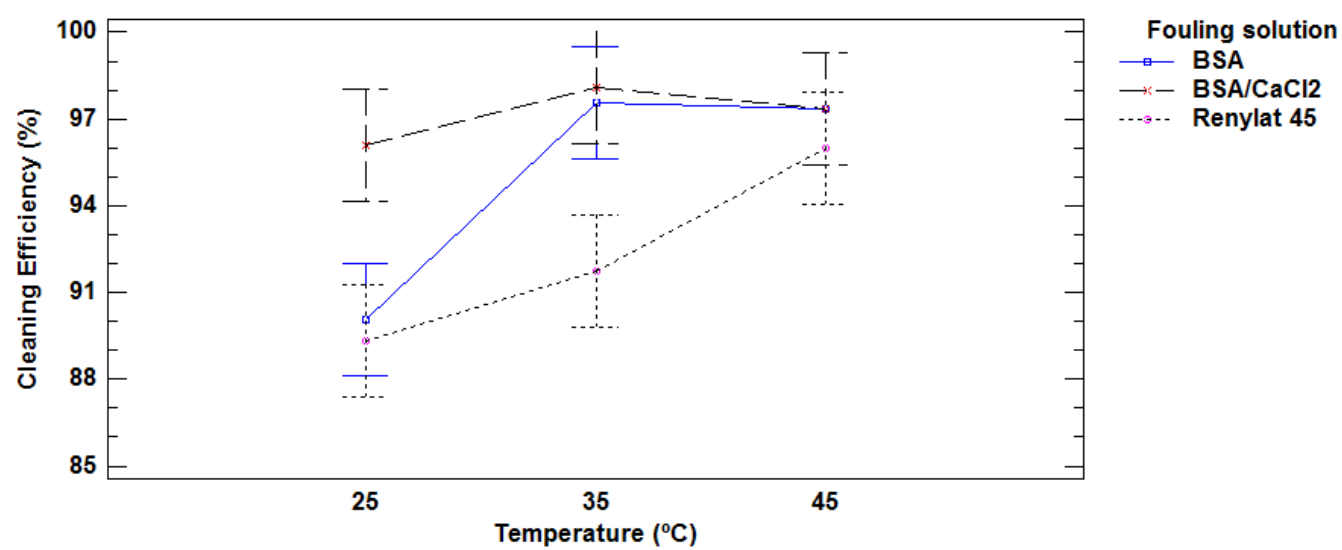

c)

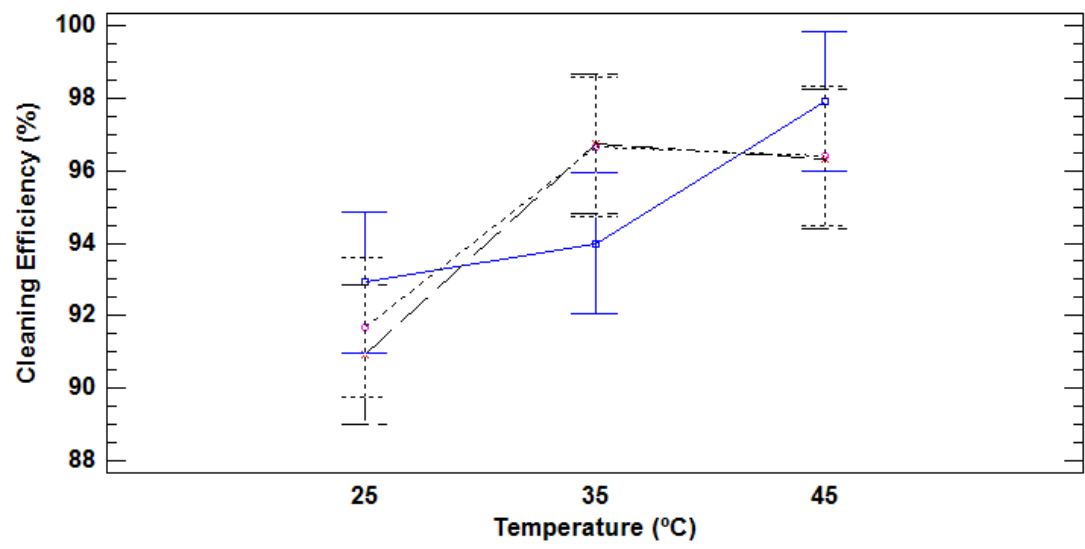

Concentration (v/v \%) $\begin{array}{ll}\longrightarrow & 0.5 \\ \longrightarrow & 0.7\end{array}$ $-.-3-0.9$

Figure 8: Factors interactions between a) temperature-membrane, b) temperature-fouling solution and c) temperature-concentration.

\section{CONCLUSIONS}

In this work, cleaning of membranes previously fouled with several whey model solutions mimicking effluents from dairy industry has been evaluated. Cleaning procedure was carried out with P3 Ultrasil 115 solution with different concentration and temperatures. Fouling of the membranes was also studied; results shown that reversible 
fouling predominate for $\mathrm{UH030}$ and irreversible fouling is more severe for UP005 membrane. In addition, among the three different fouling solutions tested, Renylat 45 caused more fouling for both membranes since the values of flux during the fouling test were the lowest and the flux decline was more pronounced in comparison with BSA and $\mathrm{BSA} / \mathrm{CaCl}_{2}$ solutions. Results from statistical analysis demonstrated that neither temperature nor concentration of the cleaning agent were statistically significant variables. The effect of US application on the cleaning solution for membrane cleaning enhancement was also evaluated. The enhancement on the cleaning efficiency values was up to $9 \%$ across de full range of the experiments. It can be concluded that the use of US technology is an effective and promising technique to enhance the cleaning efficiency. It may have an important influence on the overall process efficiency when the chemical cleaning does not reach the required efficiencies. In this work, US have been applied successfully for cleaning efficiencies lower than $95 \%$ after fouling with three different model dairy solutions.

\section{Acknowledgement}

This work was supported by the Spanish Ministry of Science and Innovation (CTM 2010-20.186).

\section{References}

AOAC Official Method 930.30, Ash of Dried Milk, First Action, 1930. 
Astudillo, C., Parra, J., González, S., Cancino, B., 2010. A new parameter fo membrane cleaning evaluation. Sep. Purif. Technol. 73, 286-293.

Bae, T.H., Tak, T.M., 2005. Interpretation of fouling characteristics of ultrafiltration membranes during the filtration of membrane bioreactor mixed liquor. J. Memb. Sci. $264,151-160$.

Cheryan, M., 1998. Ultrafiltration and Microfiltration Handbook.

Chloramine T iodometric method. Norma UNE 34826/1983, (1983).

Cuartas-Uribe, B., Alcaina-Miranda, M.I., Soriano-Costa. E., Mendoza-Roca, J.A., Iborra-Clar, M.I., Lora-García, J., 2009. A study of the separation of lactose from whey ultra filtration permeate using nano filtration. Desalination 241, 244-255.

Delaunay, D., Rabiller-Baudry, M., Gozálvez-Zafrilla, J.M., Balannec, B., Frappart, M., Paugam, L., 2008. Mapping of protein fouling by FTIR-ATR as experimental tool to study membrane fouling and fluid velocity profile in various geometries and validation by CFD simulation. Chem. Eng. Process. Process Intensif. 47, 1106-1117.

Dukhin, A.S., Parlia, S., 2014. Measuring zeta potential of protein nano-particles using electroacoustics. Colloids Surf. B. Biointerfaces 121, 257-63.

Duriyabunleng, G., Petmunee, J., Muangnapoh, J., 2001. Effect of ultrasonic waves on microfiltration in plate and frame module. J. Chem. Eng. Japan 34, 985-989.

Gsan, G., Daufin, G., Merin, U., 1995. Performance of whey crossflow microfiltration during transient and stationary operating conditions. J. Memb. Sci. 104, 271-281. 
Hausmann, A., Sanciolo, P., Vasiljevic, T., Weeks, M., Schroën, K., Gray, S., Duke, M., 2013. Fouling of dairy components on hydrophobic polytetrafluoroethylene (PTFE) membranes for membrane distillation. J. Memb. Sci. 442, 149-159.

Jun, J.Y., Nguyen, H.H., Paik, S.Y.R., Chun, H.S., Kang, B.C., Ko, S., 2011. Preparation of size-controlled bovine serum albumin (BSA) nanoparticles by a modified desolvation method. Food Chem. 127, 1892-1898.

Kazemimoghadam, M., Mohammadi, T., 2007. Chemical cleaning of ultrafiltration membranes in the milk industry. Desalination 204, 213-218.

Kulmyrzaev, A., Chanamai, R., Mcclements, D.J., 2000. Influence of $\mathrm{pH}$ and $\mathrm{CaCl} 2$ on the stability of dilute whey protein stabilized emulsions. Food Res. Int. 33, 15-20.

Kuzmenko, D., Arkhangelsky, E., Belfer, S., Freger, V., Gitis, V., 2005. Chemical cleaning of UF membranes fouled by BSA. Desalination 179, 323-333.

Kyllönen, H., Pirkonen, P., Nyström, M., Nuortila-Jokinen, J., Grönroos, A., 2006. Experimental aspects of ultrasonically enhanced cross-flow membrane filtration of industrial wastewater. Ultrason. Sonochem. 13, 295-302.

Latt, K.K., Kobayashi, T., 2006. Ultrasound-membrane hybrid processes for enhancement of filtration properties. Ultrason. Sonochem. 13, 321-328.

Lee, S., Elimelech, M., 2007. Salt cleaning of organic-fouled reverse osmosis membranes. Water Res. 41, 1134-1142.

Li, J., Sanderson, R.D., Jacobs, E.P., 2002. Ultrasonic cleaning of nylon microfiltration membranes fouled by Kraft paper mill effluent. J. Memb. Sci. 205, 247-257. 
Luján-Facundo, M.J., Mendoza-Roca, J.A., Cuartas-Uribe, B., Álvarez-Blanco, S., 2013. Ultrasonic cleaning of ultrafiltration membranes fouled with BSA solution. Sep. Purif. Technol. 120, 275-281.

Luján-Facundo, M.J., Mendoza-Roca, J.A., Cuartas-Uribe, B., Álvarez-Blanco, S., 2015. Evaluation of cleaning efficiency of ultrafiltration membranes fouled by BSA using FTIR-ATR as a tool. J. Food Eng. 163, 1-8.

Macedo, A., Duarte, E., Pinho, M., 2011. The role of concentration polarization in ultrafiltration of ovine cheese whey. J. Memb. Sci. 381, 34-40.

Marshall, A.D., Munro, P.A., Trägårdh, G., 2003. Influence of ionic calcium concentration on fouling during the cross-flow microfiltration of $\beta$-lactoglobulin solutions. J. Memb. Sci. 217, 131-140.

Maskooki, A., Kobayashi, T., Mortazavi, S.A., Maskooki, A., 2008. Effect of low frequencies and mixed wave of ultrasound and EDTA on flux recovery and cleaning of microfiltration membranes. Sep. Purif. Technol. 59, 67-73.

Matzinos, P., Álvarez, R., 2002. Effect of ionic strength on rinsing and alkaline cleaning of ultrafiltration inorganic membranes fouled with whey proteins. J. Memb. Sci. 208, $23-30$.

Merin, U., Cheryan, M., 1980. Factors affecting the mechanism of flux decline during ultrafiltration of cottage cheese whey. J. Food Process. Preserv. 4, 183-198.

Muthukumaran, S., Yang, K., Seuren, A, Kentish, S., Ashokkumar, M., Stevens, G.W., Grieser, F., 2004. The use of ultrasonic cleaning for ultrafiltration membranes in the dairy industry. Sep. Purif. Technol. 39, 99-107. 
Muthukumaran, S., Kentish, S., Ashokkumar, M., Stevens, G., 2005a. Mechanisms for the ultrasonic enhancement of dairy whey ultrafiltration. J. Memb. Sci. 258, 106-114.

Muthukumaran, S., Kentish, S., Lalchandani, S., Ashokkumar, M., Mawson, R., Stevens, G.W., Grieser, F., 2005b. The optimisation of ultrasonic cleaning procedures for dairy fouled ultrafiltration membranes. Ultrason. Sonochem. 12, 29-35.

Muthukumaran, S., Kentish, S.E., Stevens, G.W., Ashokkumar, M., Mawson, R., 2007. The application of ultrasound to dairy ultrafiltration: The influence of operating conditions. J. Food Eng. 81, 364-373.

Naddeo, V., Borea, L., Belgiorno, V., 2014. Sonochemical control of fouling formation in membrane ultrafiltration of wastewater: Effect of ultrasonic frequency. J. Water Process Eng.

Naim, R., Levitsky, I., Gitis, V., 2012. Surfactant cleaning of UF membranes fouled by proteins. Sep. Purif. Technol. 94, 39-43.

Nakanishi, K., Sakiyama, T., Imamura, K., 2001. On the adsorption of proteins on solid surfaces, a common but very complicated phenomenon. J. Biosci. Bioeng. 91, 233-244.

Narong, P., James, A.E., 2008. Efficiency of ultrafiltration in the separation of whey suspensions using a tubular zirconia membrane. Desalination 219, 348-357.

Nigam, M.O., Bansal, B., Chen, X.D., 2008. Fouling and cleaning of whey protein concentrate fouled ultrafiltration membranes. Desalination 218, 313-322.

Smith, P.K., Krohn, R.I., Hermanson, G.T., Mallia, A.K., Gartner, F.H., Provenzano, M.D., Fujimoto, E.K., Goeke, N.M., Olson, Klenk, D.C., 1985. Measurement of protein using bicinchoninic acid. Anal. Biochem. 15, 163-179. 
Popović, S., Djurić, M., Milanović, S., Tekić, M.N., Lukić, N., 2010. Application of an ultrasound field in chemical cleaning of ceramic tubular membrane fouled with whey proteins. J. Food Eng. 101, 296-302.

Popović, S.S., Tekić, M.N., Djurić, M.S., 2009. Kinetic models for alkali and detergent cleaning of ceramic tubular membrane fouled with whey proteins. J. Food Eng. 94, $307-315$.

Qu, F., Liang, H., Zhou, J., Nan, J., Shao, S., Zhang, J., Li, G., 2014. Ultrafiltration membrane fouling caused by extracellular organic matter (EOM) from Microcystis aeruginosa: Effects of membrane pore size and surface hydrophobicity. J. Memb. Sci. $449,58-66$.

Rabiller-Baudry, M., Le Maux, M., Chaufer, B., Begoin, L., 2002. Characterisation of cleaned and fouled membrane by ATR_FTIR and EDX analysis coupled with SEM: application to UF of skimmed milk with a PES membrane. Desalination 146, 123-128.

Ramachandra Rao, H.G., 2002. Mechanisms of flux decline during ultrafiltration of dairy products and influence of $\mathrm{pH}$ on flux rates of whey and buttermilk. Desalination $144,319-324$.

Rice, G., Barber, A., O’Connor, A., Stevens, G., Kentish, S., 2009. Fouling of NF membranes by dairy ultrafiltration permeates. J. Memb. Sci. 330, 117-126.

Schäfer, A.I., Fane, A.G., Waite, T.D., 2000. Fouling effects on rejection in the membrane filtration of natural waters. Desalination 131, 215-224.

Secondes, M.F.N., Naddeo, V., Belgiorno, V., Ballesteros, F., 2014. Removal of emerging contaminants by simultaneous application of membrane ultrafiltration, activated carbon adsorption, and ultrasound irradiation. J. Hazard. Mater. 264, 342-349. 
Shi, X., Tal, G., Hankins, N.P., Gitis, V., 2014. Fouling and cleaning of ultrafiltration membranes: A review. J. Water Process Eng. 1, 121-138.

Surh, J., Ward, L.S., McClements, D.J., 2006. Ability of conventional and nutritionallymodified whey protein concentrates to stabilize oil-in-water emulsions. Food Res. Int. $39,761-771$.

Tan, T.J., Wang, D., Moraru, C.I., 2014. A physicochemical investigation of membrane fouling in cold microfiltration of skim milk. J. Dairy Sci. 97, 4759-4771.

Teng, M., Lin, S., Wu, C., Juang, R., 2006. Factors affecting selective rejection of proteins within a binary mixture during cross-flow ultrafiltration. J. Memb. Sci. 281, $103-110$.

Yang, Q., Liu, Y., Li, Y., 2010. Control of protein (BSA) fouling in RO system by antiscalants. J. Memb. Sci. 364, 372-379.

Yee, K.W.K., Wiley, D.E., Bao, J., 2009. A unified model of the time dependence of flux decline for the long-term ultrafiltration of whey. J. Memb. Sci. 332, 69-80. 